\title{
Personal Employability and employment outcomes in a university sample: a study before and after COVID-19
}

\author{
Ana Hernández, Inés Tomás, Marija Davcheva, Vicente González-Romá \\ IDOCAL, University of Valencia, Spain.
}

\begin{abstract}
Labor market uncertainty makes it difficult to get (and keep) a high-quality job, even for graduate students. Moreover, this situation has worsened due to the COVID-19 pandemic. The aim of this study is to test the influence of personal employability on maintaining (or being able to find) a high-quality job in a sample of young university graduates who faced the job market crisis caused by the COVID-19 pandemic. We focus on the four personal employability dimensions of Fugate et al.'s (2004) model: career identity, personal adaptability, human capital, and social capital. Our hypotheses state that the four dimensions of employability are positively related to employment status and job quality indicators (salary, horizontal fit, job satisfaction). The results obtained in a sample of 136 university graduates show that social capital contributes to being employed after several months of job market uncertainty due to COVID-19. Moreover, career identity positively predicts horizontal fit and job satisfaction. The study shows the importance of social capital and career identity in uncertain job market situations to foster positive employment outcomes.
\end{abstract}

Keywords: Personal employability; job quality; employment status; young graduates. 


\section{Introduction}

Work is a crucial part of most people's lives, in terms of both time and significance. In the case of individuals who have earned university degrees, they are expected to not only find a job, but also to find and keep high-quality employment in return for their educational investments. However, merely having a university degree is not sufficient to get (and keep) a great job, especially under conditions of labour market uncertainty such as those recently produced by the COVID-19 pandemic. For this reason, enhancing graduates' employability has become one of the goals of the European Higher Education Area (EHEA Ministerial Conference, 2012). When addressing employability, different approaches can be used (Lo Presti \& Pluviano, 2016). We focus on personal employability or the individual factors (career identity, personal adaptability, and human and social capital) that "enable workers to identify and realize career opportunities" (Fugate et al., 2004, p. 16). Personal employability is particularly important because it does not depend on the labor market situation (Rothwell \& Rothwell, 2017), and it can be trained (e.g. Luca \& Heal, 2007, Janasz \& Forret, 2008). Taking these considerations into account, this study aims to assess the impact of personal employability on maintaining (or being able to find) a high-quality job in a sample of young university graduates who faced the job market crisis caused by the COVID-19 pandemic.

\subsection{Personal Employability}

We focus on the four personal dimensions of Fugate et al.'s (2004) model: Career identity, personal adaptability, and human and social capital. Career identity refers to who the person is or wants to be professionally, and it represents the motivational element of employability (Fugate et al., 2004). Personal adaptability refers to "the willingness and ability to change behaviors, feelings, and thoughts in response to environmental demands" (McArdle et al., 2007, p. 248), and it helps individuals to identify and realize career opportunities (Fugate et al., 2004). Human capital refers to personal factors such as education, work experience, training, knowledge, skills, and abilities (Fugate et al., 2004; McArdle et al., 2007). Specifically, we focus on generic competencies that are valued in most types of jobs (such as teamwork or time management) (Luca \& Heal, 2007). Finally, social capital refers to the interpersonal aspects of employability: networks that can provide career-related information and the opportunity to identify and fulfil career opportunities by offering guidance, sponsorship, and support (Seibert, 2001; De Janasz \& Forret, 2008).

\subsection{Job Quality}

Considering the suggestion made in the European Union's Employment in Europe (2002) report, we use González-Romá et al's (2018) multidimensional conceptualization of job quality. These authors conceptualized it as the extent to which: (1) a job has certain objective desirable characteristics; (2) there is a fit between the job requirements and the employee's 
characteristics; and (3) the job produces positive subjective experiences, such as job satisfaction. In the present study, we consider pay, the fit between graduates' field of study and their jobs (i.e. horizontal fit), and job satisfaction.

\subsection{Hypotheses}

Career identity is the motivational factor that provides graduates with direction, structure, and focus when they look for a job (McArdle et al., 2007) and, particularly, the high-quality job they want (González-Romá et al., 2018). It should also help them to make an effort to keep jobs they like. Empirical research supports these relationships (McArdle et al., 2007; Day \& Allen, 2004). Personal adaptability should help graduates to take advantage of changes and see opportunities that other individuals may not see (Van der Heijde \& Van der Heijden, 2006). This characteristic should help them to find jobs and, particularly, highquality jobs. In fact, personal adaptability is considered a key factor in career success (O'Connell et al., 2008). Regarding human capital, it is expected that individuals' investments in education and continuous development will increase their value to organizations (González-Romá et al., 2018). This should help them to find a job (or keep the jobs they have) and, especially, a job with a better salary and promotion opportunities, as found in metanalytical results ( $\mathrm{Ng}$ et al., 2005). Finally, the social resources provided by interpersonal connections (i.e. social capital) are essential for obtaining information about job opportunities and resources (Seibert et al., 2001), and they should facilitate access to (and maintenance of) employment and high-quality jobs. Empirical research supports the positive impact of social capital (e.g. González-Romá et al., 2018). Considering that the four employability dimensions are individual resources that can be especially helpful in a labor market crisis, such as the one caused by COVID-19 (Eichhorst et al., 2020; ILO \& OECD, 2020), and based on the arguments provided above, we hypothesize the following:

The four dimensions of employability will be positively related to employment status, preventing unemployment during the crisis (H1), and to job quality indicators, leading to better salaries, more horizontal fit, and greater job satisfaction (H2)

\section{Method}

\subsection{Participants and procedure}

We contracted the services of a Spanish market research company that managed a respondent panel. Employed members of its panel were invited to participate in the study, provided that they were not self-employed. Initially, 235 young (up to 30 years old) university graduates enrolled and participated at Time 1 (T1, January 2020). The COVID-19 lockdown started in March 2020. In October 2020, nine months after T1, 179 participants remained in the study at Time 2 (T2). Because we discarded 55 participants who showed careless response patterns 
on any of the three instructed response items presented at each time, the final study sample consisted of 136 graduates. Among them, 58.8\% completed a bachelor's degree, $38.2 \%$ a Master's degree, and 2.9\% a PhD. The average age was $27.2(\mathrm{SD}=2.09)$, and $45.6 \%$ were male. At T2, 85.3\% were employed, and $14.7 \%$ were unemployed. Focusing on employed participants at $\mathrm{T} 2,80 \%$ of them had the same job they had at $\mathrm{T} 1,16.9 \%$ had changed jobs once, and $3.1 \%$ had changed jobs twice.

\subsection{Measures}

Personal employability. It was measured at T1. Career identity: It was measured with González-Romá et al.'s (2018) 4-item scale, rated on a 6-point Likert scale (1. Strongly Disagree, 6. Strongly Agree). Personal Adaptability: It was measured with a 3-item scale developed for this study (e.g., "I am able to adapt to the changing circumstances of my environment"). Items were rated on a 5-point graded scale (1. Not at all, 5. A lot). Social Capital: It was measured by means of a 4-item scale based on González-Romá et al. (2018). Items were rated on a 6-point Likert scale (1. Strongly Disagree, 6. Strongly Agree). Human Capital (generic competences): It was measured with a 6-item scale based on HernándezMarch and colleagues (2009), focusing on the following competences: oral and written communication, problem solving, time and resource management, teamwork, continuous learning, and taking responsibility. Items were rated on a 5-point Likert scale (1. Low degree, 5. High degree). Cronbach's alphas ranged between .70 and .86. Exploratory factor analysis (EFA) supported the expected four-factor solution, which explained $52.51 \%$ of the variance.

Employment outcomes. They were measured at T2. Employment status was assessed by asking participants whether they were employed (1) or unemployed (0). Regarding job quality, salary was measured by asking participants about their monthly net salary, with seven response options ranging from 1 (less than $450 €$ ) to 7 (more than 2,100 €). Horizontal fit was measured by means of the following question: "To what extent is your current job related to your university degree subject?” (see González-Romá et al., 2018). The response scale ranged between 1 (not at all) and 5 (a lot). Finally, job satisfaction was measured with the 3item scale proposed by González-Romá et al. (2018), referring to participants' degree of satisfaction with the job they performed, their pay, and their opportunities for professional development. Items were rated on a 6-point Likert scale (1. Strongly Disagree, 6. Strongly Agree). In the present study. Cronbach's alpha was .75. EFA supported a one-factor solution that explained $51.95 \%$ of the variance.

\subsection{Analysis}

We controlled for gender, age, educational level, and the number of job changes during the period assessed, and we tested our hypotheses by means of Multiple Regression. When the outcome was employment status, we used logistic regression. For the three job quality 
outcomes, we used linear Regression (for horizontal fit and salary, results were crossvalidated by means of ordinal regression). All analyses were carried out with IBM-SPSS-26. Predictors were standardized for all regression analyses.

\section{Results}

Table 1 shows the descriptive statistics and correlations among the study variables.

Table 1. Means, Standard Deviations, and Correlations among variables.

\begin{tabular}{|c|c|c|c|c|c|c|c|c|c|c|c|c|c|}
\hline & Mean & $\mathrm{SD}$ & 1 & 2 & 3 & 4 & 5 & 6 & 7 & 8 & 10 & 11 & 12 \\
\hline 1. Gender T1 & .54 & .50 & & & & & & & & & & & \\
\hline 2. Age T1 & 27.20 & 2.09 & -.13 & -- & & & & & & & & & \\
\hline 3. LS T1 & 1.38 & 1.74 & -.12 & -.02 & -- & & & & & & & & \\
\hline 4. JCH & .23 & .49 & -.04 & -.07 & -.11 & -- & & & & & & & \\
\hline 5. CI T1 & 4.32 & 1.06 & -.05 & .08 & $.25^{* *}$ & -.01 & .85 & & & & & & \\
\hline 6. PA T1 & 3.97 & .69 & -.03 & .13 & .09 & .03 & $.23^{* *}$ & .86 & & & & & \\
\hline 7. $\mathrm{HC} \mathrm{T1}$ & 4.17 & .43 & .02 & .06 & -.02 & .12 & $.22^{* *}$ & $.46^{* *}$ & .70 & & & & \\
\hline 8. SC T1 & 3.19 & 1.03 & .10 & -.12 & .16 & -.08 & $.31^{* *}$ & .08 & $.25^{* *}$ & .86 & & & \\
\hline 9. ES T2 & .85 & .36 & -.05 & $.20^{*}$ & .06 & .01 & -.07 & -.06 & .02 & .16 & & & \\
\hline 10. Salary T2 & 3.88 & 1.49 & $-.19^{*}$ & -.05 & $.27 * *$ & .02 & $.23^{*}$ & .13 & .17 & .18 & -- & & \\
\hline 11. HF T2 & 2.94 & 1.33 & -.15 & .05 & $.58^{* *}$ & -.01 & $.43^{* *}$ & $.19^{*}$ & .14 & $.19^{*}$ & $.26^{* *}$ & -- & \\
\hline 12. JS T2 & 3.95 & 1.06 & -.18 & .03 & $.30^{* *}$ & .07 & $.43^{* *}$ & .14 & .07 & $.20^{*}$ & $.49^{* *}$ & $.45^{* *}$ & .75 \\
\hline
\end{tabular}

Note. LS: Level of studies achieved; JCH: Job changes over time, CI: Career Identity; PA: Personal Adaptability; HC: Human Capital; SC: Social Capital; ES: Employment Status; HF: Horizontal Fit; JS: Job Satisfaction * $p<$. $05 ; * * p<.01$. Reliabilities are shown on the diagonal. Salary, GF, and JS obtained only in employed participants. Thus, column 9 is not shown because job status is a constant when correlated with Salary, GF, and $J S$.

Table 2 shows the results of the multiple regression analysis. Focusing on employment status at T2, social capital is the only employability dimension that enhances the probability of being employed about seven months after the COVID-19 crisis started. Contrary to our expectations, career identity is negatively related to employment status. In the case of job quality, only career identity was positively and significantly related to two of the three job quality indicators considered: horizontal educational fit and job satisfaction. These results partially support our two hypotheses. 
Table 2. Regression Analysis.

\begin{tabular}{lcccc}
\hline Predictors & ES T2 & Salary T2 & HF T2 & JS T2 \\
\hline Gender T1 & .02 & $-.59^{*}$ & -.31 & $-.32^{*}$ \\
Age T1 & $.37^{*}$ & -.06 & -.00 & -.01 \\
CI T1 & $-.67^{*}$ & .19 & $.45^{* *}$ & $.38^{* *}$ \\
PA T1 & -.17 & .08 & .14 & .09 \\
HC T1 & .11 & .17 & .04 & -.07 \\
SC T1 & $.87^{* *}$ & .15 & .08 & .12 \\
\hline
\end{tabular}

Note. CI: Career Identity; PA: Personal Adaptability; HC: Human Capital; SC: Social Capital; ES: Employment Status; HF: Horizontal Fit; JS: Job Satisfaction. Regression coefficients are unstandardized $* p<.05$; $* *<<.01$ (one-tailed tests for regression coefficients). Only control variables that show significant effects are included.

\section{Discussion}

The results obtained show that only one of the dimensions of Fugate et al.'s personal employability model, social capital, contributes to being employed after several months of job market uncertainty caused by COVID-19. Interestingly, although career identity is negatively related to employment status, it positively predicts several job quality indicators in employed graduates, particularly horizontal fit and job satisfaction.

Contrary to our expectations, personal adaptability is not related to any of the employment outcomes considered. The fact that the study was carried out during the pandemic may contribute to more adaptable individuals accepting a bad situation in these unexceptional times if they do not have strong career identities. For other individuals with high personal adaptability and strong career identities, the results may be more positive. Future research should explore the impact of the interaction between personal adaptability and career identity. Regarding human capital, although our results suggest that university degrees protect graduates from unemployment (only $12.7 \%$ of the participants lost the jobs they had at T1 and were unemployed, a percentage much lower than the general population under 30), generic competences do not play a role in fostering good employment outcomes (at least among university graduates). Future research should consider whether the importance of particular generic competences depends on the type of job.

It is important to point out that our study has a number of limitations. First, the sample size was small, especially when focusing on job quality indicators, which limits the generalizability of the results. Second, the study relies on self-reported data. It would be interesting to include the employer's perspective to understand what dimensions of personal 
employability are considered crucial, especially in uncertain situations. Despite these limitations, the results have several important implications.

\subsection{Theoretical implications}

The pattern of results shows the need to differentiate between the four dimensions of personal employability because the effects of different dimensions depend on the employment outcome: employment status or job quality. Interestingly, whereas career identity fosters employment quality in uncertain contexts, individuals with strong career identities may prefer to stay unemployed (at least for a while), rather than accepting a job that does not match who they want to be professionally. These questions deserve further research that analyzes the role of moderators that may influence the effects of career identity.

\subsection{Practical implications}

Because there is evidence that the professional and practical orientation of university instruction improves some employability dimensions, such as career identity, as well as job quality indicators over time (e.g. vertical educational fit) (González-Romá et al., 2015a, 2015b), universities should work on developing instruction programs and counseling strategies designed to develop, at the very least, social capital and career identity.

\subsection{Conclusions}

Despite the aforementioned limitations of the study, our results show the importance of social capital and career identity in uncertain job market situations to foster positive employment outcomes.

\section{Acknowledgements}

This work was supported by research grants provided by the Spanish Ministry of Economy and Competitiveness (MINECO), the Spanish State Research Agency (AEI), and the European Regional Development Fund (ERDF) [Ref. PSI2017-86882-R].

\section{References}

Day, R., \& Allen, T. D. (2004). The relationship between career motivation and self-efficacy with protege' career success. Journal of Vocational Behavior, 64, 72-91. doi:10.1016/S0001-8791(03)00036-8

De Janasz, S. C., \& Forret, M. L. (2008). Learning The Art of Networking: A Critical Skill for Enhancing Social Capital and Career Success. Journal of Management Education, 32(5), 629-650. doi:10.1177/1052562907307637

EHEA Ministerial Conference. (2012). Making the Most of Our Potential: Consolidating the European Higher Education Area, Bucharest Communiqué. 26-27 
Eichhorst, W., Marx, P., \& Rinne, U. (2020). Manoeuvring Through the Crisis: Labour Market and Social Policies During the COVID-19 Pandemic. Intereconomics, 55(6), 375 380. doi: 10.1007/s10272-020-0937-6

European Commission. (2002). Employment in Europe 2002. Recent trends and prospects. Luxembourg: Office for Official Publications of the European Communities.

Fugate, M., Kinicki, A. J., \& Ashforth, B. E. (2004). Employability: A psycho-social construct, its dimensions, and applications. Journal of Vocational Behavior, 65(1), 14 38. doi:10.1016/j.jvb.2003.10.005

González-Romá, V.; Hernández, A., \& Gamboa, J. (2015a, June). Instructional factors and over-education of university graduates. In 1st International Conference on Higher Education Aadvances (HEAD'15) (pp. 57-60). Editorial Universitat Politècnica de València.

González-Romá, V.; Hernández, A., Gamboa, J., Peiró, J.M. \& Gracia (2015b, April). Factors influencing graduates' overeducation trajectories: a Latent Growth Curve Analysis. In A. Luksyte (Chair), New trends in overqualification research. Symposium conducted at the 30th Annual SIOP Conference. Philadelphia, USA

González-Romá, V., Gamboa, J. P., \& Peiró, J. M. (2018). University Graduates' Employability, Employment Status, and Job Quality. Journal of Career Development, 45(2), 132-149. doi: 10.1177/0894845316671607

ILO \& OECD (2020). The Impact of the COVID-19 Pandemic on Jobs and Incomes in G20 Economies. ILO-OECD Paper Prepared at the Request of G20 Leaders, Saudi Arabia's G20 Presidency, G20 Saudi Arabia, 1-46.

Lo Presti, A., \& Pluviano, S. (2016). Looking for a route in turbulent waters Employability as a compass for career success. Organizational Psychology Review, 6(2), 192-211. doi: $10.1177 / 2041386615589398$

Luca, J., \& Heal, D. (2007, June). Producing graduates with essential generic skills: A model for teaching and learning. In EdMedia + Innovate Learning (pp. 2883-2891). Association for the Advancement of Computing in Education (AACE).

McArdle, S., Waters, L., Briscoe, J. P., \& Hall, D. T. (2007). Employability during unemployment: Adaptability, career identity and human and social capital. Journal of Vocational Behavior, 71(2), 247-264. doi:10.1016/j.jvb.2007.06.003

Ng, T. W. H., Eby, L. T., Sorensen, K. L., \& Feldman, D. C. (2005). Predictors of objective and subjective career success: A meta-analysis. Personnel Psychology, 58(2), 367-408. doi:10.1111/j.1744-6570.2005.00515.x

O'Connell, D. J., McNeely, E., \& Hall, D. T. (2008). Unpacking personal adaptability at work. Journal of Leadership \& Organizational Studies, 14(3), 248-259. doi:10.1177/1071791907311005

Rothwell A., \& Rothwell, F. (2017) Graduate Employability: A Critical Oversight. In M. Tomlinson, \& L. Holmes (Eds.), Graduate Employability in Context (pp. 41-63). London: Palgrave Macmillan. doi:10.1057/978-1-137-57168-7_2

Seibert, S., Kraimer, M., \& Crant, J. (2001). What do proactive people do? A longitudinal model linking proactive personality and career success. Personnel Psychology, 54(4), 845-874. doi:10.1111/j.1744-6570.2001.tb00234.x 
Van der Heijde, C. M., \& Van der Heijden, B. I. J. M. (2006). A competence-based and multidimensional operationalization and measurement of employability. Human Resource Management, 45(3), 449-476. doi:10.1002/hrm.20119. 